\title{
Electrochemical and Spectroscopic Analyses of Lithium Ion Conductive Polymers Prepared by the Copolymerization of Ionic Liquid Monomer with Lithium Salt Monomer
}

\author{
Wataru OgIHARA, Norio SuZuKI, Nobuhumi NAKAmura, and Hiroyuki OHNO ${ }^{\dagger}$ \\ Department of Biotechnology, Tokyo University of Agriculture and Technology, \\ 2-24-16 Naka-cho, Koganei 184-8588, Japan
}

(Received July 22, 2005; Accepted September 12, 2005; Published February 15, 2006)

\begin{abstract}
Lithium ion conductive polymer electrolytes have been prepared by copolymerization of an imidazolium salt type ionic liquid monomer; 1-(1-acryloyloxyhexyl)-3-ethylimidazolium bis(trifluoromethanesulfonyl)imide with polyether-containing salt monomer with low glass transition temperature; methacryloyloxy octa(ethylene oxide)2-sulfobenzoate lithium salt. The ampholytic copolymers were obtained as flexible and transparent films. Their ionic conductivity and glass transition temperature depended on monomer mixing ratio. Some copolymers containing higher lithium salt monomer fraction than that of ionic liquid monomer had lithium ion transference number exceeding 0.5. Against these, high ionic conductivity was found in the copolymers with high ionic liquid monomer fraction. Copolymerization of monomers containing either ionic liquid unit or lithium salt unit provided ion conductive polymers with a wide variety of conductive characteristics. [DOI 10.1295/polymj.38.117]

KEY WORDS Ionic Liquid / Polymer Electrolyte / Lithium Ion Transference Number / Raman Spectroscopy /
\end{abstract}

Ionic liquids (ILs) are usually realized as highly ion conductive, non-volatile and non-flammable media. ${ }^{1,2}$ These ILs are expected to be applied as non-flammable ion conductive materials instead of volatile organic solvents. ${ }^{3-15}$ Solidification of ILs is also important for light weight and small ionics devices. For example, thermally stable ion conductive gels have been prepared by mixing ILs (or IL derivatives) with polyelectrolytes containing fixed anionic sites and free cations such as lithium ions. ${ }^{7,16}$ The gel based ILs often had a high ionic conductivity depending on the ILs content. The gel type polymers composed of poly(methacryloyloxy octa(ethylene oxide)-2-sulfobenzoate lithium salt) and 1-ethyl-3-methylimidazolium bis(trifluoromethanesulfonyl)imide ([EMIm][TFSI]) had a lithium ion transference number $\left(\mathrm{t}_{\mathrm{Li}+}\right)$ below 0.1 in our preliminary experiments. This is comprehended as the competitive migration of lithium cation, TFSI anion, and component ions. Thus our goal is to increase the ion transference number of polymers without serious drop of the ionic conductivity.

To make polyelectrolytes with high lithium ion conductivity, we must suppress the migration of component ions of ILs so that only the lithium cation in the IL matrix is transported. One method to realize this is the use of a zwitterion that is composed of an onium cation and an anion tethered with molecular spacer. ${ }^{17-19}$ Another is the use of polymerized ILs, in which the IL component ions are fixed on the poly- mer chains. ${ }^{20-22}$ The advantages of polymerized ILs are the structural diversity of the polymers and the tunability of conduction characteristics as well as mobile ion species by changing polymer structure. ${ }^{22}$ Therefore, lithium ion conductive polymers should be synthesized by copolymerization of two monomers with one having an IL structure and the other having a lithium salt structure.

\section{EXPERIMENTAL}

\section{Materials}

The sources of the chemicals were as follows. $\mathrm{N}$ Ethylimidazole, 2-sulfobenzoic anhydrate and 6-bromo-1-hexanol were purchased from Tokyo Kasei. Acryloyl chloride was purchased from Aldrich. Lithium bis(trifluoromethanesulfonyl)imide (LiTFSI) was a gift from Sumitomo $3 \mathrm{M}$. Polyethylene glycol monomethacrylate was a gift from NOF Co. Lithium carbonate and $\alpha, \alpha^{\prime}$-azobis(isobutyronitrile) (AIBN) were purchased from Kanto Chemicals. AIBN was recrystallized from methanol before use as an initiator for radical polymerization. All other reagents were used as received. Lithium metal with a thickness of $100 \mu \mathrm{m}$ was purchased from Honjo Chemical Corporation.

\section{Preparation of Monomers}

We prepared 3-(6-acryloyloxyhexyl)-1-ethylimidazolium TFSI (C6EIm) according to the method we

${ }^{\dagger}$ To whom correspondence should be addressed (Tel/Fax: +81-42-388-7024, E-mail: ohnoh@cc.tuat.ac.jp). 

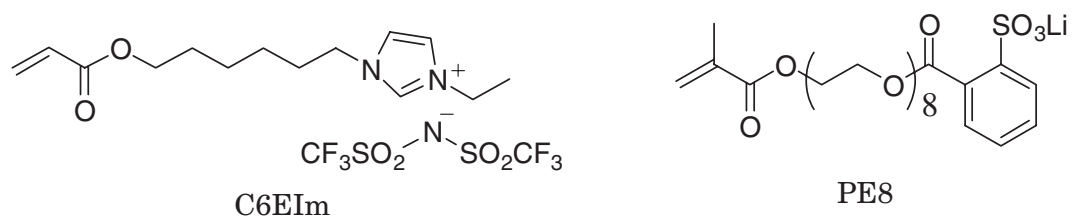

Scheme 1. Structure of monomers.

used previously. ${ }^{21}$ To a tetrahydrofuran solution of 6bromo-1-hexanol $(3.72 \mathrm{~g}, 20 \mathrm{mmol})$ and slightly excess triethylamine $(2.29 \mathrm{~g}, 22 \mathrm{mmol})$ cooled with ice, a tetrahydrofuran solution of slightly excess acryloyl chloride ( $2.04 \mathrm{~g}, 22 \mathrm{mmol}$ ) was added dropwise. Gentle mixing of this solution for $12 \mathrm{~h}$ at room temperature produced 1-bromohexyl-6-acrylate. The 1-bromohexyl-6-acrylate sample was then reacted with one and a half molar amount of $\mathrm{N}$-ethylimidazole in ethanol at room temperature for $24 \mathrm{~h}$. After the ethanol was removed by evaporation, the residual compound was washed with diethyl ether twice to exclude unreacted compounds. Then, a conventional method ${ }^{2}$ was used to substitute the bromide anions of the obtained salt with TFSI anions. C6EIm was obtained by evaporating the liquids under reduced pressure at room temperature for one night. ${ }^{1} \mathrm{H}$ NMR $\left(\mathrm{CDCl}_{3}\right)$ : $\delta 1.30$ (quint, $2 \mathrm{H}$ ), 1.40 (quint, $2 \mathrm{H}$ ), $1.56(\mathrm{t}, 3 \mathrm{H}$ ), 1.68 (quint, 2H), 1.90 (quint, 2H), $4.14(\mathrm{t}, 2 \mathrm{H}), 4.19$ $(\mathrm{t}, 2 \mathrm{H}), 4.26(\mathrm{q}, 2 \mathrm{H}), 5.82(\mathrm{~d}, 1 \mathrm{H}), 5.84-6.10(\mathrm{q}$, $1 \mathrm{H}), 6.40(\mathrm{~d}, 1 \mathrm{H}), 7.34(\mathrm{~s}, 1 \mathrm{H}), 7.63(\mathrm{~s}, 1 \mathrm{H}), 8.83$ (s, 1H).

Methacryloyl octa(ethylene oxide)-2-sulfobenzoate lithium salt (PE8) was prepared according to our previous method. ${ }^{23}$ Polyethylene glycol monomethacrylate was reacted with an equimolar amount of 2-sulfobenzoic anhydrate in chloroform at room temperature for $12 \mathrm{~h}$. The resulting sulfonic acid monomer was then neutralized with lithium carbonate to obtain lithium salt monomer (PE8). After evaporation of solvent, obtained viscous liquid was washed twice with diethyl ether. PE8 was obtained by evaporating the liquids under reduced pressure at room temperature for one night. ${ }^{1} \mathrm{H}$ NMR $\left(\mathrm{CDCl}_{3}\right): \delta 1.94(\mathrm{~s}, 3 \mathrm{H}), 3.42-3.76$ (broad, $\left.-\mathrm{CH}_{2} \mathrm{CH}_{2} \mathrm{O}-\right), 5.58(\mathrm{~d}, 1 \mathrm{H}), 6.11(\mathrm{~d}, 1 \mathrm{H}), 7.40$ $(\mathrm{m}, 2 \mathrm{H}), 7.51(\mathrm{~m}, 2 \mathrm{H})$. The structure of C6EIm and PE8 is shown in Scheme 1.

\section{Copolymerization}

We mixed C6EIm and PE8 at a suitable molar ratio and then added $1 \mathrm{~mol} \%$ AIBN as a radical initiator to the vinyl group. The mixture was stirred until it became homogeneous, and then it was injected into a 0.5 -mm-thick space between two glass plates. This spacing was maintained by using a Teflon ${ }^{\circledR}$ spacer. The mixture was kept at $70^{\circ} \mathrm{C}$ for $24 \mathrm{~h}$ to copolymerize PE8 and C6EIm. Then the resulting compounds were washed with chloroform and dried at $80^{\circ} \mathrm{C}$ under reduced pressure for $24 \mathrm{~h}$.

\section{Methods}

The structure of the monomers was studied using ${ }^{1} \mathrm{H}$ NMR spectroscopy (JEOL $\alpha-500$ NMR spectrometer).

The ionic conductivity of the prepared polymers was measured using an impedance analyzer (Schlumberger Solartron 1260 impedance/gain-phase analyzer) with the complex-impedance method at frequencies from $10 \mathrm{~Hz}$ to $1 \mathrm{MHz}$. The dynamic ionic conductivity measurement system developed in our laboratory $^{24}$ was used to depict Cole-Cole plots in the temperature range 10 to $60^{\circ} \mathrm{C}$ by collecting complex impedance data while the sample was cooled at 2.5 ${ }^{\circ} \mathrm{Cmin}^{-1}$. All measurements were done in a glove box filled with dry $\mathrm{N}_{2}$.

The lithium ion transference number $\left(\mathrm{t}_{\mathrm{Li}+}\right)$ of the polymers was measured using the method reported by Ogata et ll $^{25}$ In this method, $\mathrm{t}_{\mathrm{Li}+}$ is assumed to be the ratio of the conductivity as determined from the direct current polarization to that determined from the complex impedance. All measurements were done in a glove box filled with dry argon. A $100-\mu$ m-thick lithium metal foil was attached to a stainless steel plate (SUS 314) and used as an active electrode. The [SUS|Li|polymer|Li|SUS] cells were assembled and were used for both the direct current polarization and the complex impedance measurements. In the direct current measurement, a constant potential of $10 \mathrm{mV}$ was applied to the cell until the current reached a constant value.

DSC measurements were done with a DSC-120 (Seiko Instruments) in the temperature range -130 to $200{ }^{\circ} \mathrm{C}$ with a heating rate of $10^{\circ} \mathrm{C} \mathrm{min}^{-1}$. The thermal stability of the resulting polymers was investigated using a TG/DTA 220 (Seiko Instruments) from 25 to $450{ }^{\circ} \mathrm{C}$ with heating rate of $10^{\circ} \mathrm{C} \mathrm{min}^{-1}$.

The Raman spectra were obtained using a JASCO NRS-1000 spectrometer with a Kaiser Optical holographic super-notch filter and a liquid $\mathrm{N}_{2}$-cooled CCD detector. Data were accumulated for $200 \mathrm{~s}$ with the spectral resolution of $0.6 \mathrm{~cm}^{-1}$. The excitation source was a Coherent Innova 90C $\mathrm{Kr}$ laser with a $20 \mathrm{~mW}$ beam at a $647.1 \mathrm{~nm}$ excitation wavelength. Spectra were collected on samples in bulk condition 
Table I. Thermal properties of homopolymers and copolymers

\begin{tabular}{ccccc}
\hline Abbreviation & $\mathrm{C} 6 \mathrm{EIm} / \mathrm{mol} \%$ & $\mathrm{PE} 8 / \mathrm{mol} \%$ & $T_{\mathrm{g}} /{ }^{\circ} \mathrm{C}$ & $T_{\mathrm{d}} /{ }^{\circ} \mathrm{C}$ \\
\hline Poly(PE8) & 0 & 100 & -14 & 304 \\
$\mathrm{C} 1$ & 25 & 75 & -22 & 277 \\
$\mathrm{C} 2$ & 33 & 67 & -16 & 303 \\
$\mathrm{C} 3$ & 50 & 50 & -29 & 318 \\
$\mathrm{C} 4$ & 66 & 34 & -32 & 282 \\
$\mathrm{C} 5$ & 75 & 25 & -38 & 300 \\
Poly $(\mathrm{C} 6 \mathrm{EIm})$ & 100 & 0 & -59 & 381 \\
\hline
\end{tabular}

at room temperature using a backscattering geometry. The peak frequencies were calibrated relative to an indene standard and are accurate to $\pm 1 \mathrm{~cm}^{-1}$.

\section{RESULTS AND DISCUSSION}

\section{Copolymer Structure}

Copolymerized ILs (CoILs) were prepared by the radical polymerization of C6EIm and PE8 with various molar ratio, hereafter these copolymers were abbreviated as $\mathrm{C} 1$ to $\mathrm{C} 5$ with the larger number having the greater mole fraction of C6EIm in feed. Their mole fractions and thermal properties are in Table I. Homopolymers of PE8 or C6EIm, hereafter, poly(PE8) or poly (C6EIm), individually, were also prepared and characterized (Table I). Poly(PE8) was obtained as a self-standing film, whereas poly(C6EIm) was sticky solid. Of course, since polymer properties should relate with average molecular weight, we cannot discuss these properties with only characteristics of the corresponding monomers. We however had no information about the average molecular weight of these polymers.

\section{Thermal Properties of CoILs}

Thermal properties of CoILs are also shown in Table I. Poly(C6EIm) showed low glass transition temperature $\left(T_{\mathrm{g}}\right)$ of $-59^{\circ} \mathrm{C}$ that we attribute to the effect of the hydrocarbon spacer between the polymer main chain and the imidazolium cation unit. This low value is consistent with our previous observation that the mobility of component ions of imidazolium cations remains high even after polymerization. ${ }^{21,22}$ Also the $T_{\mathrm{g}}$ of CoILs decreased with increasing C6EIm monomer fraction. We suggested that the plasticization effect of TFSI anion in imidazolium salt contributed to the low values of $T_{\mathrm{g}}$ of CoILs.

Thermal decomposition temperature $\left(T_{\mathrm{d}}\right)$ of poly(PE8) was detected at $304^{\circ} \mathrm{C}$. The $T_{\mathrm{d}}$ values of $\mathrm{C} 1$ to $\mathrm{C} 5$ were in the range between 277 and $318^{\circ} \mathrm{C}$. On the other hand, poly(C6EIm) showed high $T_{\mathrm{d}}$ of around $400{ }^{\circ} \mathrm{C}$ (Table I). We attribute the relatively poor thermal stability of CoILs to the relatively low thermal stability of PE8 unit. Probably the ether unit structure

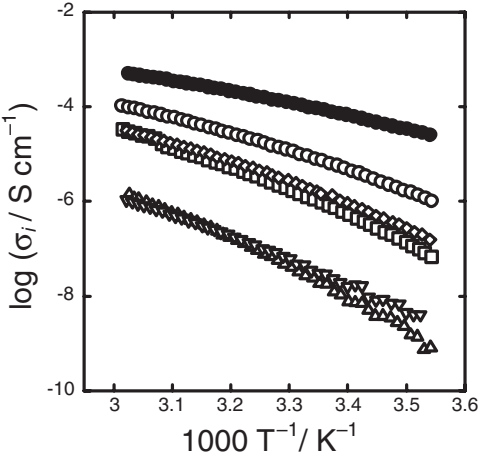

Figure 1. Ionic conductivities of poly(C6EIm) (•) and CoILs:C1 $(\nabla), \mathrm{C} 2(\triangle), \mathrm{C} 3(\diamond), \mathrm{C} 4(\square), \mathrm{C} 5(\bigcirc)$.

is the least thermally stable unit in the polymer. For the design of thermally stable polymer electrolytes, ionic liquid moiety is indispensable if the kind of carrier ion was not important factor.

\section{Ionic Conductivity of CoILs}

We measured the ionic conductivity of the CoILs. The ionic conductivity of poly(PE8) is around $10^{-9}$ $\mathrm{S} \mathrm{cm}^{-1}$ at $30^{\circ} \mathrm{C}$ and the conductivity monotonically increases with increasing C6EIm fraction (Figure 1). The ionic conductivity depends on both mobility and the number of carrier ions in the ion conductive matrix. An increase of C6EIm fraction in CoILs results in an increase of the number of carrier ions. Thus, it is likely that the increase of TFSI anion in CoILs makes their ionic conductivity higher. In addition, the decrease of $T_{\mathrm{g}}$ with increasing C6EIm fraction should also increase the ionic conductivity of the CoILs. This argument is supported by the clear relationship between the ionic conductivity and $T_{\mathrm{g}}$ values of the CoILs in Figure 2. The segmental motion of matrix polymers has important role to transport ions because the ionic conductivity is the function of $T_{\mathrm{g}}$.

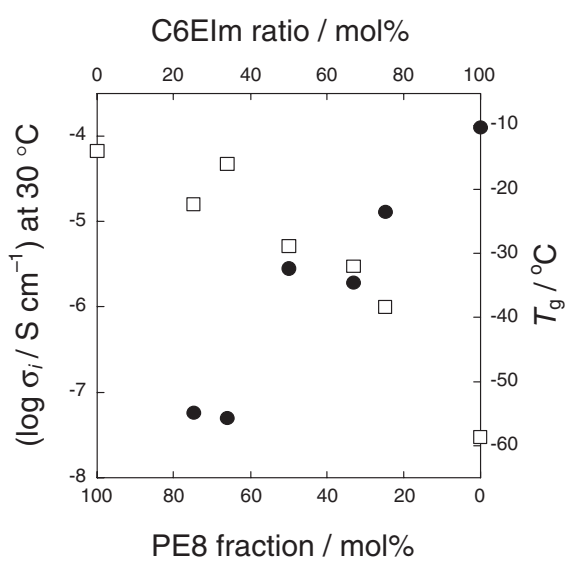

Figure 2. Ionic conductivity $(\bullet)$ and glass transition temperature ( $\square$ ) for CoILs of various monomer composition. 
W. OGIHARA et al.

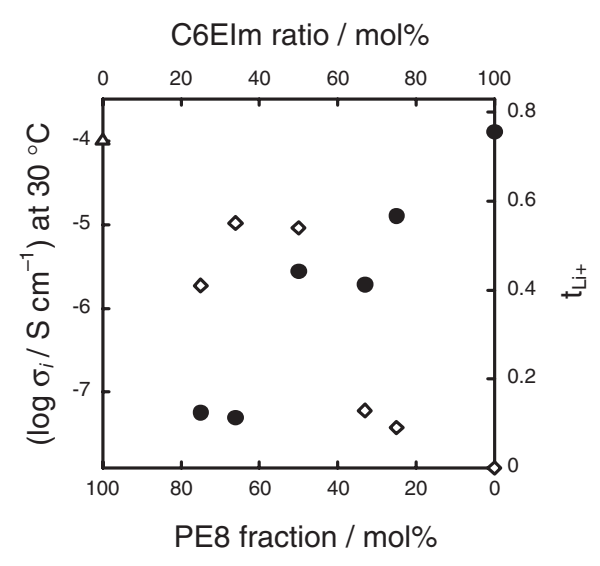

Figure 3. Ionic conductivity $(\bullet)$ and lithium ion transference number $(\diamond, \triangle)$ for CoILs of various monomer composition.

For the ion transport, ionic liquid domains contributed more to prepare conduction paths than polyethers having charges on the chain end.

\section{Lithium Ion Transference Number of the CoILs}

The $\mathrm{t}_{\mathrm{Li}+}$ and the ionic conductivity at $30^{\circ} \mathrm{C}$ of CoILs are plotted against the monomer mixing ratio in Figure 3. We measured the $t_{\mathrm{Li}+}$ of poly(PE8) at $84^{\circ} \mathrm{C}$ because of its very low ionic conductivity. In contrast to the ionic conductivity, the $\mathrm{t}_{\mathrm{Li}+}$ of CoILs increased with increasing PE8 fraction except $\mathrm{C} 1$. Therefore, lithium salt content in CoILs directly related to the $\mathrm{t}_{\mathrm{Li}+}$ of the CoILs. The value of $\mathrm{t}_{\mathrm{Li}+}$ is not as high as that of poly(PE8), but the value of around 0.5 at $30^{\circ} \mathrm{C}$ is a good value for bi-ion conductive systems. In ordinary polyether type matrix, $\mathrm{t}_{\mathrm{Li}+}$ is around 0.2 or less because cations are trapped by the polyether segments through ion-dipole interaction whereas anions are relatively free. The increase of ionic conductivity with PE8 is likely to be mainly due to the migration of TFSI anion, and this is consistent with the $\mathrm{t}_{\mathrm{Li}+}$ decreasing with an increase of the ionic conductivity. However, the high $t_{\mathrm{Li}+}$ of the CoILs with more than $50 \mathrm{~mol} \%$ PE8 indicates that lithium cation also moves as a carrier ion as well as the TFSI anion. Taking both the ionic conductivity and the $\mathrm{t}_{\mathrm{Li}+}$ into account, $\mathrm{C} 3$ has good performance as a lithium ion conductive polymer material.

\section{Raman Spectroscopic Study for CoILs}

The copolymerization of PE8 with C6EIm would allow higher mobility of lithium ion generated from PE8. The ionic conductivity should be influenced by the number of the carrier ion and the mobility of ions. Raman spectroscopy is a powerful tool to determine ion states, so we used this method to clarify the degree of dissociation in CoILs.

For all samples except poly(PE8), a Raman band appeared in the region of $740-750 \mathrm{~cm}^{-1}$ (Figure 4).

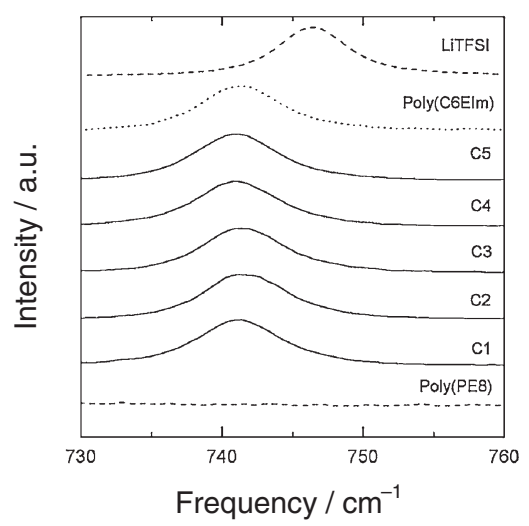

Figure 4. Raman spectra of CoILs of various monomer composition, poly(PE8), poly(C6EIm) and solid state LiTFSI.

This band is attributed to a symmetric bending vibration of the $\mathrm{CF}_{3}$ group $\delta_{\mathrm{s}}\left(\mathrm{CF}_{3}\right)$ of the TFSI anion. ${ }^{26}$ The $\delta_{\mathrm{s}}\left(\mathrm{CF}_{3}\right)$ band of the free TFSI anion appears at $740 \mathrm{~cm}^{-1}$ in Figure 4. For ion pairs and aggregates, this peak shifted to higher frequencies. ${ }^{26-28}$ From the measured shift, we can quantify the amount of free ions, ion pairs, and aggregates. The $\delta_{\mathrm{s}}\left(\mathrm{CF}_{3}\right)$ band of poly(C6EIm) occurs at $741 \mathrm{~cm}^{-1}$, whereas that of solid LiTFSI occurs at $747 \mathrm{~cm}^{-1}$. In the case of EMImTFSI, the $\delta_{\mathrm{s}}\left(\mathrm{CF}_{3}\right)$ band was detected at around $740 \mathrm{~cm}^{-1}$ (data not shown). These results demonstrate that almost all of the TFSI anion in poly(C6EIm) are present as free ions even after polymerization. Moreover, the $741 \mathrm{~cm}^{-1}$ values of CoILs are closer to that of poly (C6EIm) than that of poly(PE8). We can therefore conclude that the copolymerization of C6EIm with PE8 hardly affects the degree of dissociation of TFSI salts.

To determine the degree of dissociation of the sulfonate moiety, particular attention was given to the Raman band in the region of $1000-1100 \mathrm{~cm}^{-1}$, which is attributed to the symmetric stretching vibration of sulfonate moiety, $v_{\mathrm{s}}\left(\mathrm{SO}_{3}\right){ }^{29}$ It is known that the $v_{\mathrm{S}}\left(\mathrm{SO}_{3}\right)$ band of the free sulfonate can be observed at $1032 \mathrm{~cm}^{-1}$ and this band shifts to $1042 \mathrm{~cm}^{-1}$ when the $\mathrm{SO}_{3}{ }^{-}$ion pairs with $\mathrm{Li}^{+}$and shifts to $1052 \mathrm{~cm}^{-1}$ in the aggregated state. ${ }^{29,30}$ However, estimates based on the original Raman spectra of CoILs are difficult because the $v_{\mathrm{s}}\left(\mathrm{SO}_{3}\right)$ band of the sulfonate moiety is too close to the $-\mathrm{SO}_{2}-$ symmetric stretching mode of the TFSI anion (which is at about $1030 \mathrm{~cm}^{-1}$ ). Therefore, we obtained the difference spectra by subtracting the Raman spectrum of poly(C6EIm) from the CoIL spectra, and the spectrum of poly(C6EIm) intensities were adjusted based on the C6EIm/PE8 molar ratio. The results are shown in Figure 5. The $v_{\mathrm{s}}\left(\mathrm{SO}_{3}\right)$ bands around $1040 \mathrm{~cm}^{-1}$ in all difference spectra mean that the sulfonate group in each CoIL forms an ion pair. Poly(PE8) also has a $1040 \mathrm{~cm}^{-1}$ 


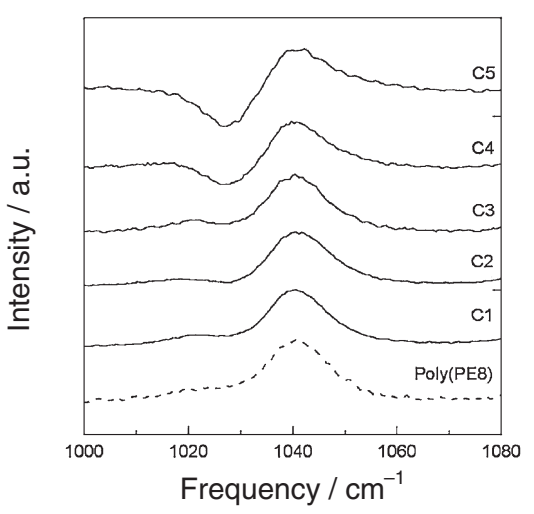

Figure 5. Raman (differential) spectra of CoILs and poly(PE8).

band, which indicates that the imidazolium salt group is hardly affected by the degree of dissociation of lithium sulfonate in the CoILs. These results indicate that better $t_{\mathrm{Li}+}$ values are attributable to the increase in lithium ion mobility.

\section{CONCLUSIONS}

The ionic conductivity and thermal properties of copolymerized ionic liquids (CoILs) were studied as a function of monomer composition. We conclude that copolymerization of ionic liquid monomers (C6EIm) with a lithium salt monomer (PE8) results in a polymer having good lithium ion transport properties. We found that the conductivity increased with increasing C6EIm fraction. On the other hand, higher $t_{\mathrm{Li}+}$ values were found by increasing the PE8 monomer fraction. In order to study the dissociation state of these copolymers, CoILs were analyzed by Raman spectroscopy. The $\delta_{\mathrm{s}}\left(\mathrm{CF}_{3}\right)$ band was clearly observed at around $741 \mathrm{~cm}^{-1}$ indicating that TFSI anions in the polymer were free. Against this, the $v_{\mathrm{s}}\left(\mathrm{SO}_{3}\right)$ band at around $1040 \mathrm{~cm}^{-1}$ showed that the dissociated lithium sulfonates formed ion pairs.

Acknowledgment. The present work was carried out under the 21st Century COE program of "Future Nano-Materials" in Tokyo University of Agriculture and Technology. The study was supported by a Grant-in-Aid for Scientific Research from the Ministry of Education, Culture, Sports, Science and Technology, Japan (No. 17073005 and 17205020). We acknowledge Sumitomo $3 \mathrm{M}$ for their kind donation of reagents.

\section{REFERENCES}

1. J. S. Wilkes and M. J. Zaworotko, J. Chem. Soc., Chem. Commun., 965 (1992).

2. P. Bonhôte, A. P. Dias, M. Armand, N. Papageorgiou, K.
Kalyanasundaram, and M. Grätzel, Inorg. Chem., 35, 1168 (1996).

3. M. Doyle, S. K. Choi, and G. Proulx, J. Electrochem. Soc., 147, 34 (2000).

4. M. A. B. H. Susan, A. Noda, S. Mitsushima, and M. Watanabe, Chem. Commun., 938 (2003).

5. R. T. Carline, H. C. DeLong, J. Fuller, and P. C. Trulove, J. Electrochem. Soc., 141, L73 (1994).

6. V. R. Koch, C. Nanjundiah, G. B. Appetecchi, and B. Scrosati, J. Electrochem. Soc., 142, L116 (1995).

7. H. Sakaebe and H. Matsumoto, Electrochem. Commun., 5, 594 (2003).

8. H. Nakagawa, S. Izuchi, K. Kuwana, T. Nukuda, and Y. Aihara, J. Electrochem. Soc., 150, A695 (2003).

9. W. Lu, A. G. Fadeev, B. Qi, E. Smela, B. R. Mattes, J. Ding, G. M. Spinks, J. Mazurkiewics, D. Zhou, G. G. Wallace, D. R. MacFarlane, S. A. Forsyth, and M. Forsyth, Science, 297, 983 (2002).

10. H. Matsumoto, T. Matsuda, T. Tsuda, R. Hagiwara, M. Ito, and Y. Miyazaki. Chem. Lett., 30, 26 (2001).

11. S. Mikoshiba, S. Murai, H. Sumino, and S. Hayase, Chem. Lett., 31, 1156 (2002).

12. P. Wang, S. M. Zakeeruddin, P. Comte, I. Exnar, and M. Grätzel, J. Am. Chem. Soc., 125, 1166 (2003).

13. C. Nanjundiah, S. F. McDevitt, and V. R. Koch, J. Electrochem. Soc., 144, 3392 (1997).

14. A. B. McEwen, H. L. Ngo, K. LeCompte, and J. L. Goldman, J. Electrochem. Soc., 146, 1687 (1999).

15. M. Ue, M. Takeda, A. Toriumi, A. Kominato, R. Hagiwara, and Y. Ito, J. Electrochem. Soc., 150, A499 (2003).

16. J. Sun, D. R. MacFarlane, and M. Forsyth, Solid State Ionics, 147, 333 (2000).

17. C. Tiyspiboomchaiya, J. M. Pringle, J. Sun, N. Bryne, P. C. Howlett, D. R. MacFarlane, and M. Forsyth, Nat. Mater, 3, 29 (2004).

18. M. Yoshizawa, M. Hirao, K. Ito-Akita, and H. Ohno, J. Mater. Chem., 11, 1057 (2001).

19. M. Yoshizawa, A. Narita, and H. Ohno, Aust. J. Chem., 57, 139 (2004).

20. H. Ohno and K. Ito, Chem. Lett., 27, 751 (1998).

21. M. Yoshizawa and H. Ohno, Electrochim. Acta, 46, 1723 (2001).

22. S. Washiro, M. Yoshizawa, H. Nakajima, and H. Ohno, Polymer, 45, 1577 (2004).

23. K. Ito, Y. Tominaga, and H. Ohno, Electrochim. Acta, 42, 1561 (1997).

24. H. Ohno, Y. Inoue, and P. Wang, Solid State Ionics, 62, 257 (1993).

25. Y. Kato, M. Watanabe, K. Sanui, and N. Ogata, Solid State Ionics, 40/41, 632 (1990).

26. Z. Wang, W. Gao, X. Huang, Y. Mo, and L. Chen, J. Raman Spectrosc., 32, 900 (2001).

27. I. Rey, J. C. Lassegues, J. Grondin, and L. Servant, Electrochim. Acta, 43, 1505 (1998).

28. L. Edman, J. Phys. Chem. B, 104, 7254 (2000).

29. W. Huang, R. Frech, and R. A. Wheeler, J. Phys. Chem. B, 98, 100 (1994).

30. A. Ferry, G. Orädd, and P. Jocobsson, Electrochim. Acta, 43, 1471 (1998). 